\title{
Way to Foster the Application-oriented Talents in Civilian-Run Colleges
}

\author{
Chunshan Yang ${ }^{1}$ Xiaofeng $\mathrm{Li}^{2}$ \\ 1 Department of Computer Science and Technology, Cheng-Dong College of Northeast \\ Agricultural University, Harbin 150025, China \\ ycszy1999@126.com \\ 2 Department of Informatics and Science, Heilongjiang International University, Harbin \\ 150025, China \\ mberse@126.com
}

\begin{abstract}
Keyword: civilian-run colleges; cooperation of Production-Academy-Research; practical talents; cultivating of talents
\end{abstract}

\begin{abstract}
Construction of talent training mode in civilian-run colleges should be closely combined with the running mode and operation characteristics, and must comply with ability of student. Learning consciousness of the student in civilian-run colleges is generally poor, but they have strong ability of social activities, strong hands-on skill, and ability of applying knowledge, so their innovation activities is more towards the actual activities rather than basic theory. They are suitable for cultivating of the practical according to their quality, ability and value orientation. Integration of production-study-research is a main trend of cultivating practical talents in civilian-run colleges. It takes example for College of Cheng-dong University of Northeast Agricultural, demonstrate how to deals with the relation between production, study and research based on the particularity of civilian-run colleges in this paper. At last, suggestions about mode of the cooperation of Production-Academy-Research from internal guarantee and external mechanism would be given.
\end{abstract}

\section{Introduction}

There are 698 civilian-run colleges with 5,050,700 students in 2011, accounting for $21.87 \%$ of all college students[1]. Deficiencies are existed in both understanding and management, which directly effects on the quality of cultivating of talents in civilian-run colleges.

First, there is not sufficient fund in the good running of civilian-run colleges. The money went into civilian-run colleges basically originate from enterprise, private investment and fees from the students etc, and without country fund, nonprofit funds for education and social donation[2]. Lack of funding result in that teaching infrastructure in civilian-run colleges is remote from standards released by the Ministry of Education, and it is neither meet the need to improve the conditions for running schools nor meet the need to expand the schools, thus great effects upon the teaching result.

Secondly, there need a well-structured, high-level education, good professional quality of teachers to cultivate practical innovative talents. The younger teachers are in the majority among all the full-time teachers in civilian-run colleges, there is lack of academic leaders, there can hardly be academic echelon[3]. At the same time, there are great deals of difficulties in application of research projects and academic result appraisal.

Thirdly, civilian-run colleges have yet to establish systematic and holistic system of teaching management, which is based on teaching evaluation; there is a not formed scientific, effective, and simple method of teaching evaluation that more tailored to meet its own need[4].

Finally, compared with students from public colleges, students from civilian-run colleges have little self-control, lack of learning enthusiasm[5], at the same time, there have weaknesses in the curriculum, course content, teaching method and teaching management etc. which influence to some extent student's learning interest and attitude.

\section{A New Approach of the Cooperation of Production-Academy-Research}


As a civilian-run college that put on official record of the Ministry of Education, College of Cheng-dong University of Northeast Agricultural was established under the approval of the Heilongjiang People's Government in May 2002. In early 2009, computer department of the College has spearheaded the " $3+1$ " Cooperation of Production-Academy-Research. As a new model of applied talents training, the so-called " $3+1$ " pattern of training talent is that take specialized theory primarily, professional practice as auxiliary during the first three years, but in the fourth year students concentrate on learning practical knowledge that take professional practice primarily, specialized theory as auxiliary[6,7].

\section{Improve Quality of Talents Training by the Fusion of Production-Academy}

Adjust Curriculum. It must revise talent cultivation plans according to " $3+1$ " cooperation of university-enterprise, aim at serving the student, orient at job-hunting, strengthen their sense of colleges and universities, stand out professional character and level, for these, the department divide curriculums into general education curriculum, specialized courses, major directional courses, post group course, and their respective teaching hours as shown in Figure 1.

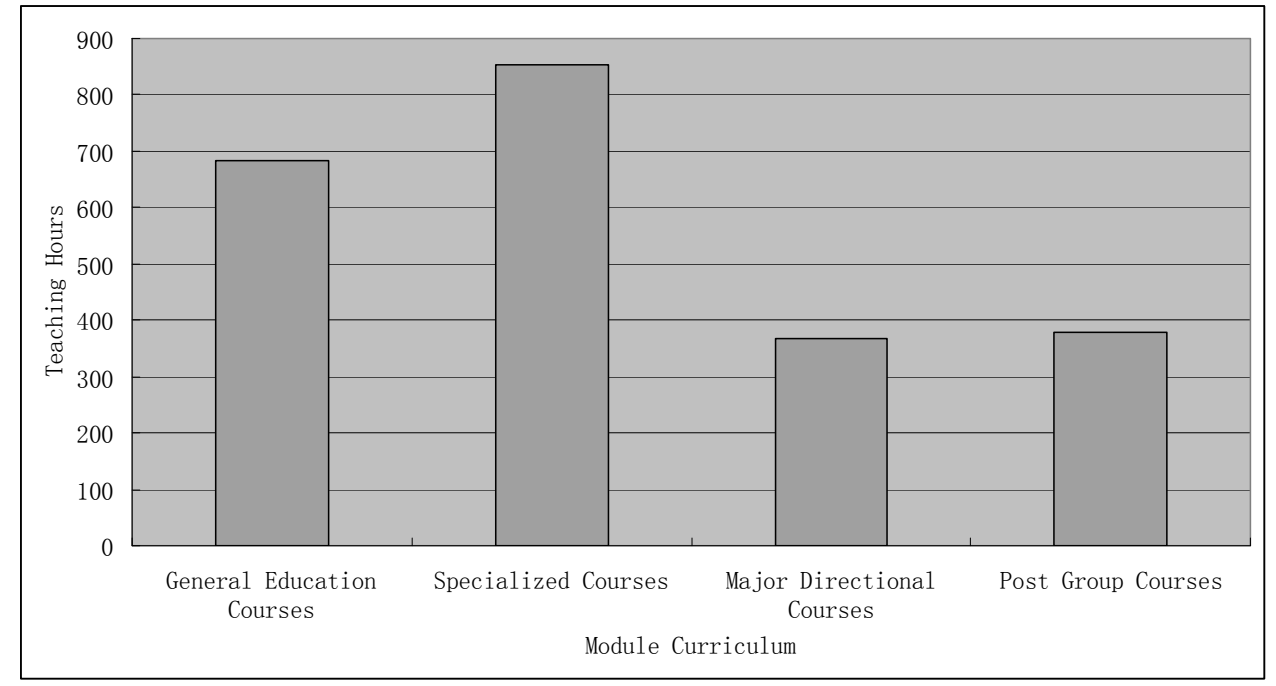

Fig. 1 the Methods for Dividing Courses

Enhance Teaching in Special English. As a general language of computer and the IT industry, English is can not be replaced by other language. Learn the computer skills need to master and utilize the computer professional English. The students of computer science have poor English, which makes English teaching quite difficult. In order to improve the students' ability of professional English, "three one" special English teaching activities is developed by career-oriented majors in computer science and technology. The "three one" special English teaching activities, namely is word in every class, sentence in every week, one essay in every term, which will play an important role in improving the students' English ability.

Enhance the Employment Rate by the Cooperation of University-Enterprise. A good number of graduates from Department of Computer Science can practice in enterprise before graduation, and therefore promoted from intern to permanent staff annually. Adhere the way to cooperation of university-enterprise, which makes the employment rate of Department of Computer Science reached over 95\% in successive years, as shown in Figure 2.

\section{Improve the Quality of Talents Training by the Fusion of Educational and Research}

In the building of scientific research, Cheng-dong College start college research, education reform, quality course and other quality engineering construction, encouraging teachers to produce more teaching and scientific researching results, and which supply a basis for the further declare provincial-level scientific research project. At the same time, the college creates the Division of Science and Technology to manage and service teaching and scientific researching work, and 
commend and reward for outstanding scientific research results, thus fire the enthusiasm of all scientific research.

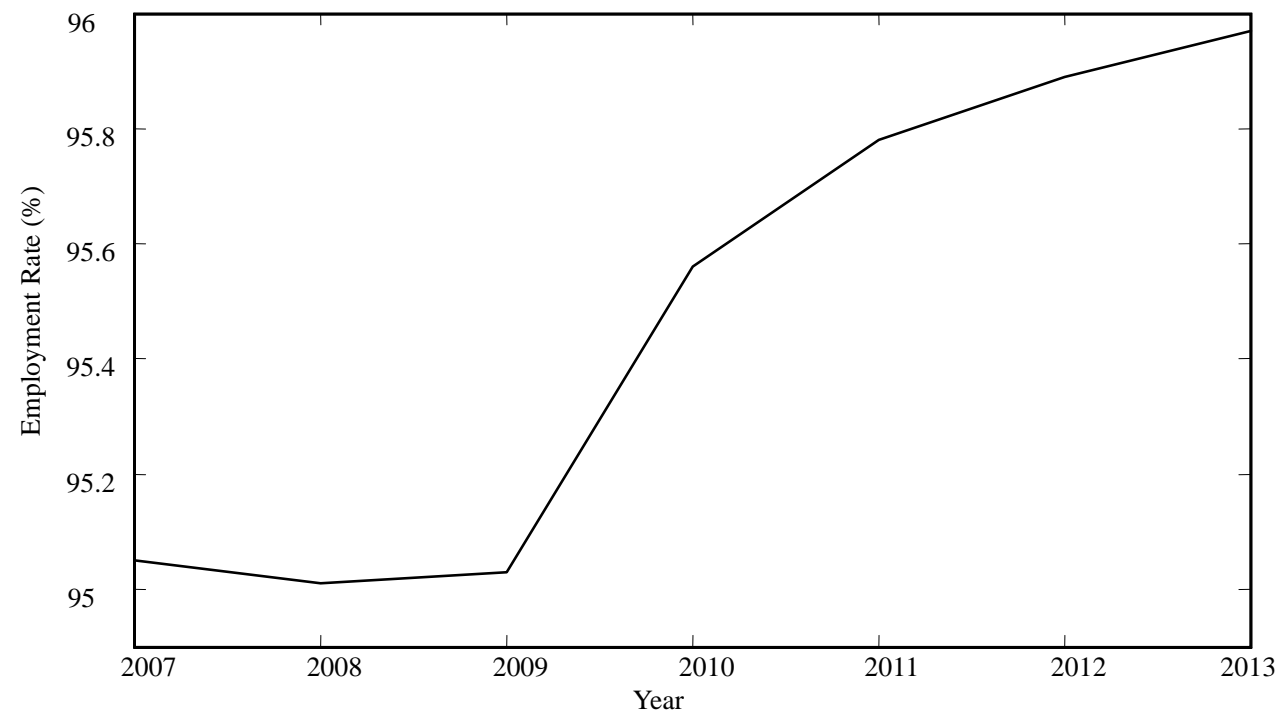

Fig. 2 the Employment Rate of Department of Computer Science since 2007

Build a Team with Higher Research Level Through Innovative Ideas. Cheng-dong College employs the retired professor from famous universities, and makes it possible for them to contribute all they can, for example, Professor Zhou Hongyu, retired from Harbin University of Science and Technology, organize teachers to write teaching materials, and guide teachers to apply for provincial-level scientific research project since 2012, thus fire the enthusiasm of all scientific research. Moreover, Associate Professor Li Xiaofeng, PhD Student of Beijing Institute of Technology, was hired by Department of Computer Science as the Leading Talent for teaching and scientific research. The overall level of scientific research has improved a lot in this way in 2012, as shown in Table 2.

\begin{tabular}{c|c|c|c}
\multicolumn{5}{c}{ Table 2 Scientific Research in 2012 } \\
\hline Papers & Textbooks & Reconstruction projects & Patents \\
\hline 85 & 13 & 16 & 5 \\
\hline
\end{tabular}

Strengthen Guidance to Apply for Project, Encourage Academic Exchanges with the Outside World. The college organizes various forms of academic exchange activities regularly, and invites well-known scholars and experts to communicate with teachers, and encourages teachers to academic exchanges with the outside world. In 2012, 4 teachers successively attend international academic conferences held in Beijing and Taiyuan, and give Assembly panel presentation. Department of Computer Science co-organizes the 2013 international academic conference on Computer Science, Electronics Technology and Intelligent System. The college organizes the 2013 international academic conference on System Control, Simulation and Modeling. These strengthen academic exchange with experts and scholars from home and abroad by such platform for the exchange of information technology, and improve the academic influence of teachers on the field of computer, data modeling, information and control.

Create College Newspaper, and Provide an Academic Platform for Teachers. With the vigorous development of educational cause, the College creates College newspaper. The Series grounded on the education and teaching characteristics of civilian-run colleges and make itself in feature of serving teachers, students and teaching research, with combinations of the " $3+1$ " pattern of training talent, mainly focus on new progress of student management and teaching management.

\section{Raise the Level of the Teachers by the Fusion of Enterprise and Research}

The Department of Computer Science sent full-time teachers into the cooperative enterprise to study, for example, Beida Jade Bird, DHC software, Neusoft, ChinaSoft International, Tatsu Technology, and so on. The teachers improve greatly their practice ability by learning, as shown in 
Figure 3. At the same time, the Department encourages teachers to participate in a professional skills training regularly, such as Huawei certified instructor, Network engineering supervisor, Oracle certified instructor, etc. and improve the overall level of raise the teachers.

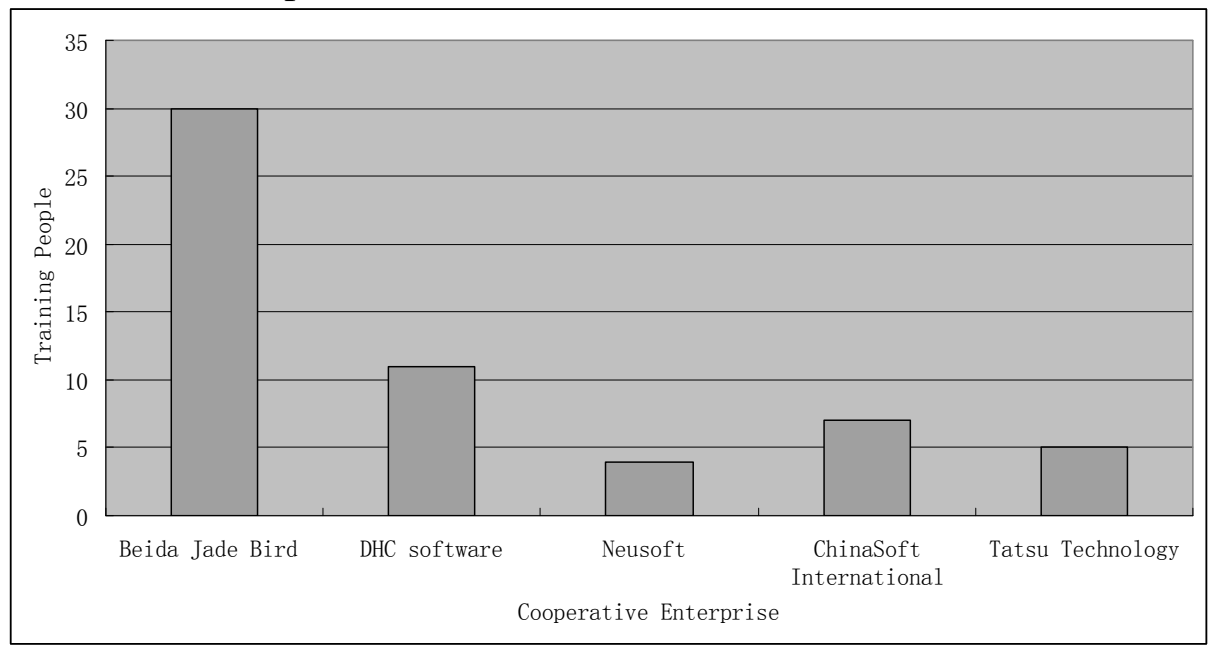

Fig. 3 Full-time Teachers Learning Situation in Cooperative Enterprise

\section{Summary}

Conclusions as a result, in the process of promotion of professional disciplines and cultivating of talents, scientific research will play an important role. Cultivating of teacher quality and practical abilities is vitally important to improving scientific research level. The teacher quality will have a direct impact on each student's ability. The Cooperation of Production-Academy-Research is a systematic engineering, and is a cooperation of production, study, scientific research and practical application. The co-education in producing, teaching and researching, which make full use of the respective advantages of cultivating of talents among college, enterprise and scientific research, is organically combined schooling that teaching knowledge is the major task and production that gain practical ability is the major task. The co-education in producing, teaching and researching is of great significance and far-reaching impact for the living and development of civilian-run colleges.

\section{References}

[1] The Sate Council. National Education Reform and Development of Long-term Planning Programs (2010-2020) [Z]. 2010-07-29.

[2] Fang Hui. Research on teachers' research work in New-established College --The Case of Bijie College [D]. East China Normal University. 2009

[3] Xuan Lina, He Maobing, Qian Junpin, etc. On the Cultivation of Teachers' Scientific Research Ability as the Core Competence In Private Colleges [J]. Journal of Jiangxi Institute of Education(Comprehensive). 2012(12).

[4] Peng Xu. Study on Cooperation Mode of Production, Teaching and Research in Local Universities from the Perspective of Practical Talents [J]. 2010(13):143-145

[5] Cao Shoujin, Xu Qingjun, Zhu Yulin, etc. Enterprise-university-research Cooperating Models in Foreign Countries and Their Enlightenment [J]. Journal of Central South University of Forestry \&Technology(Social Sciences), 2010,4(3):84-87

[6] Luo Jianwen. Constructing Professional Group of Computer Specialties Based on Professional Position Groups[J]. Journal of Qingyuan Polytechnic, 2012,6(5):75-76

[7] Wang Xi. Reseach on the Education Modes of Independent College[D]. Dalian University of Teehnology. 2010. 